\title{
Characteristics of vegetation succession on the Pinus thunbergii forests in warm temperate regions, Jeju Island, South Korea
}

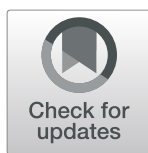

Yongsik Hong ${ }^{1}$, Euijoo Kim² ${ }^{2}$ Eungpill Lee ${ }^{2}$, Seungyeon Lee ${ }^{2}$, Kyutae Cho², Youngkeun Lee ${ }^{3}$, Sanghoon Chung ${ }^{3}$, Heonmo Jeong ${ }^{4}$ and Younghan You ${ }^{*^{*}}$ (1)

\begin{abstract}
Background: To investigate the trends of succession occurring at the Pinus thunbergii forests on the lowlands of Jeju Island, we quantified the species compositions and the importance values by vegetation layers of BraunBlanquet method on the Pinus thunbergii forests. We used multivariate analysis technique to know the correlations between the vegetation group types and the location environmental factors; we used the location environment factors such as altitudes above sea level, tidal winds (distance from the coast), annual average temperatures, and forest gaps to know the vegetation distribution patterns.

Results: According to the results on the lowland of Jeju Island, the understory vegetation of the lowland Pinus thunbergii forests was dominated by tall evergreen broad-leaved trees such as Machilus thunbergii, Neolitsea sericea, and Cinnamomum japonicum showing a vegetation group structure of the mid-succession, and the distribution patterns of vegetation were determined by the altitudes above sea level, the tidal winds on the distance from the coast, the annual average temperatures, and the forest gaps. We could discriminate the secondary succession characteristics of the Pinus thunbergii forests on the lowland and highland of Jeju Island of South Korea.

Conclusions: In the lowland of Jeju Island, the secondary succession will progress to the form of Pinus thunbergii (early successional species) $\rightarrow$ Machilus thunbergii, Litsea japonica (mid-successional species) $\rightarrow$ Machilus thunbergii (late-successional species) sequence in the temperate areas with strong tidal winds. In the highland of Jeju Island, the succession will progress to the form of Pinus thunbergii (early successional species) $\rightarrow$ Neolitsea sericea, Eurya japonica (mid-successional species) $\rightarrow$ Castanopsis sieboldii (late-successional species) sequence in the areas where tidal winds are weak and temperatures are relatively low. However, local differences between lowland and highland of Jeju Island will be caused by the micro-environmental factors resulting from the topographic differences and the supply of tree seeds. From the characteristics of succession study, we could properly predict and manage the Pinus thunbergii forest ecosystem on lowland and highland of Jeju Island.
\end{abstract}

Keywords: Evergreen broad-leaved tree, Jeju Island, Environmental factors, Pinus thunbergii, Secondary succession

\section{Background}

Globally, the distribution areas of evergreen broadleaved forests are present in wide areas in the intermediate areas between the tropical regions and the temperate regions above and below the equator in terms of latitudes, that is, north and south latitudes of $30 \sim 40^{\circ}$, but

\footnotetext{
* Correspondence: youeco21@kongju.ac.kr

${ }^{1}$ Korea Environmental Preservation Association, Daejeon 35235, Republic of Korea

Full list of author information is available at the end of the article
}

the distribution areas are not very large (World Conservation Monitoring Centre (WCMC) 1992). That is, South Korea is a peninsula located between north latitudes 33 and $43^{\circ}$, which corresponds to the evergreen broad-leaved forest distribution zone together with East Asia, the Florida peninsula in North America, and the Mediterranean climate region in Europe (Wang 1961; Mucina et al. 1997; Box 1988; Klötzli 1988; Song 1988; Bunyavejchewin 1999; Fuziwara and Box 1999; José et al. 2008; Song and Da 2016), and is divided into subalpine

(c) The Author(s). 2019 Open Access This article is distributed under the terms of the Creative Commons Attribution 4.0 International License (http://creativecommons.org/licenses/by/4.0/), which permits unrestricted use, distribution, and reproduction in any medium, provided you give appropriate credit to the original author(s) and the source, provide a link to the Creative Commons license, and indicate if changes were made. The Creative Commons Public Domain Dedication waiver (http://creativecommons.org/publicdomain/zero/1.0/) applies to the data made available in this article, unless otherwise stated. 
forest, cold temperate forest, and warm temperate forest regions depending on the climate conditions (Yim and Kira 1975).

The main distribution areas of warm temperate evergreen broad-leaved forests in South Korea are centered on the south coast and island areas and reach Chun Island in Ulsan, Gyeongsangnamdo, and Ulleung Island in Gyeongsangbukdo in the east coast and Baengnyeong Island, Daecheong Island, and Socheong Island in the west coast (Kim and Oh 1996). Among the islands, Jeju Island is a representative island located in the southernmost of South Korea and is a warm temperate evergreen broadleaved forest area when seen in terms of vegetation belts (Cha 1969). Representative tree species in Jeju Island include Machilus thunbergii, Neolitsea sericea, Castanopsis sieboldii, Camellia japonica, and Quercus acuta, which are all evergreen broad-leaved tree species (Yim 1989).

Pinus thunbergii is one of afforestation tree species, which constitute the maritime forests of South Korea, because of its rapid initial growth rate and strong resistance to salt damage (Kim 2003). In particular, since the low temperatures in winter due to the effects of the oceanic climate limit the distribution of Pinus thunbergii, lowlands at levels below the altitude above sea level of $500 \mathrm{~m}$ can be seen as the main distribution areas of Pinus thunbergii. That is, the most suitable location environment for Pinus thunbergii to grow naturally is inland coastal areas including Jeju Island (National Institute of Forest Science 2013), and Pinus thunbergii is already distributed in the Jeju Island forest area at a high ratio of $27 \%$ (Jeju Island Special Self-Governing Province 2014).

Evergreen broad-leaved forest zones in the warm temperate zone in South Korea have been rapidly destroyed in the past due to various anthropogenic disturbances, including deforestation, fuel gathering, collection of decorative plants, grazing for income growth, facility disposition for industrial facilities, and the rapid increase in tourists (Oh and Choi 1993), and original form of natural vegetation landscapes has been lost due to Pinus thunbergii forest belts (Yim 1989; Oh and Choi 1993). However, on reviewing the currently existing evergreen broad-leaved forest distribution areas in South Korea, it can be seen that, although most of the regions have degenerated vegetation, where Pinus thunbergii is dominant as a result of the secondary succession, they are very highly likely to be restored into the original evergreen broad-leaved forests because saplings of Machilus thunbergii, Neolitsea sericea, Castanopsis sieboldii, etc. are growing vigorously (Kim and Oh 1996).

Studies conducted on Pinus thunbergii forests in South Korea include those regarding vegetation and group structures (Lee and Kwon 1988; Baek 1996; Ha 1998; Choi et al. 2012; Park et al. 2013; Kim et al. 2016), those regarding location classification and distribution (Kim et al. 1981; Kim and Kil 1983), those regarding strand management and growth models (Park et al. 2015), and those regarding planting models (Kwon et al. 2004). However, most of the studies examined only those Pinus thunbergii forests that are distributed along the inland coastal areas, and studies on the Pinus thunbergii forests in Jeju Island, which are representative evergreen needle-leaf tree forests in Jeju Island, are extremely rare. Furthermore, in the case of foreign countries, studies on Pinus thunbergii forests were conducted in multilateral aspects such as seeking practical management plans through associations between vegetation types (Stanfield et al. 2001), correlations with location environmental factors, vegetation succession, pests, and land use $\mathrm{C} \mathrm{Su}-$ zuki and Numata 1982; Taoda 1988; Nakashima 2005; Masaka et al. 2012).

Currently, Pinus thunbergii forests in the lowlands of Jeju Island have been continuously damaged by mountain area development, and the damage caused by pine wilt disease is also very serious. In addition, those stresses caused by biotic and abiotic factors due to the rapid climate change since the mid-twentieth century have direct and indirect effects on the growth environment. The most efficient way to respond to the foregoing problems is forming sustainable and stable forests through the restoration of multi-layered structures from the simple forests dominated by Pinus thunbergii by introducing evergreen broad-leaved tree species (Yim et al. 1990), which are potential natural vegetation of Jeju Island (Park et al. 2009).

In addition, scientific data on the process of natural succession are indispensable for environment-friendly and ecological sustainable management of damaged forests (Lee et al. 2004). The foregoing not only can help understand the process of forest development but also can be directly applied to the setting of criteria for forest restoration and management (Kang 1982; Lee 1995; Lee et al. 2004).

Therefore, this study quantitatively analyzed the vegetation structure and group classification of the forests of Pinus thunbergii, which is a representative evergreen needle-leaf tree distributed in the lowlands of Jeju Island, and major location environmental factors that affect the foregoing with a view to examining the vegetation succession stage into evergreen broad-leaved forests, which are potential natural vegetation $(\mathrm{PNV})$.

\section{Materials and methods}

\section{Overall situation of the survey area}

Jeju Island, which is the survey area in this study, is an isolated ecosystem in an island in east longitudes of $126^{\circ}$ $08^{\prime} \sim 126^{\circ} 58^{\prime}$ and north latitudes of $33^{\circ} 06^{\prime} \sim 34^{\circ} 00^{\prime}$ located in the South Sea of the Korean Peninsula. The 
surrounding waters are the South Sea including the Jeju Island Strait on the north and the East China Sea on the south. Therefore, Jeju Island is on the boundary between the South Sea and the East China Sea and shows the characteristics of oceanic climates, which are warm and moist throughout the year because it is surrounded by the sea on four sides.

The annual average temperature is $11.7^{\circ} \mathrm{C}$, and months in which the temperature drops below 0 can be hardly seen. Over the last 30 years, Jeju Island showed mild temperature distributions with the annual average temperatures of Jeju-si and Seogwipo at $15.2^{\circ} \mathrm{C}$ and $15.9^{\circ} \mathrm{C}$, respectively. The annual average precipitation in the entire Jeju Island over the last 30 years is $2044 \mathrm{~mm}$ while that in coastal lowlands is $1560 \mathrm{~mm}$. Therefore, coastal lowlands are the rainiest areas in South Korea. The seasonal distribution of precipitation is relatively even but is characterized by the spring rainy season. In addition, Jeju Island is a volcanic island formed by the eruption of alkaline lava flows, and Halla Mountain with an altitude of $1950 \mathrm{~m}$ is located in the center of the island. The slopes are steeper in areas closer to the center, but the base areas form flat lowlands with slopes of about $5^{\circ}$ (Jeju Island Special Self-Governing Province 2014).

Jeju Island has a total forest area of 88,247 ha (National Institute of Forest Science 2013). Out of the 88,247 ha, the area of pure Pinus thunbergii simple forests is 15,721 ha and that of mixed strand forests with Pinus thunbergii is 7974 ha. These forests account for a high ratio of forests in Jeju Island to the extent that they account for $27 \%$ of the total forest area in Jeju Island (Jeju Island special self-governing province 2014). However, these forests are being damaged or converted into lands for other uses every year due to mountain area development and external disturbance.

\section{Vegetation survey and data analysis}

The survey was conducted on the Pinus thunbergii forests, which are mainly distributed in the lowlands of Jeju Island at altitudes below $500 \mathrm{~m}$ above sea level. The survey period was from March to October 2015 with a total of 56 stands of Pinus thunbergii forests with relatively stable layer structure and good species composition (Fig. 1). The sizes of the survey pots were set to the minimum areas that could represent the species composition of the stands by referring to the height of trees that were dominant in the tree layer, and sizes set appropriately as such were $10 \times 10 \mathrm{~m}, 15 \times 15 \mathrm{~m}$, and $20 \times 20 \mathrm{~m}$.

The vegetation survey divided the vegetation at the site according to the heights of tree crowns into a tree layer $(\geq 8 \mathrm{~m})$, a subtree layer $(4-8 \mathrm{~m})$, a shrub layer $(1-4 \mathrm{~m})$, and a herb layer $(\leq 1 \mathrm{~m})$, and the integrated dominance values of Braun-Blanquet, Plant sociology (1965) were applied to appearing tree species. In addition, environmental

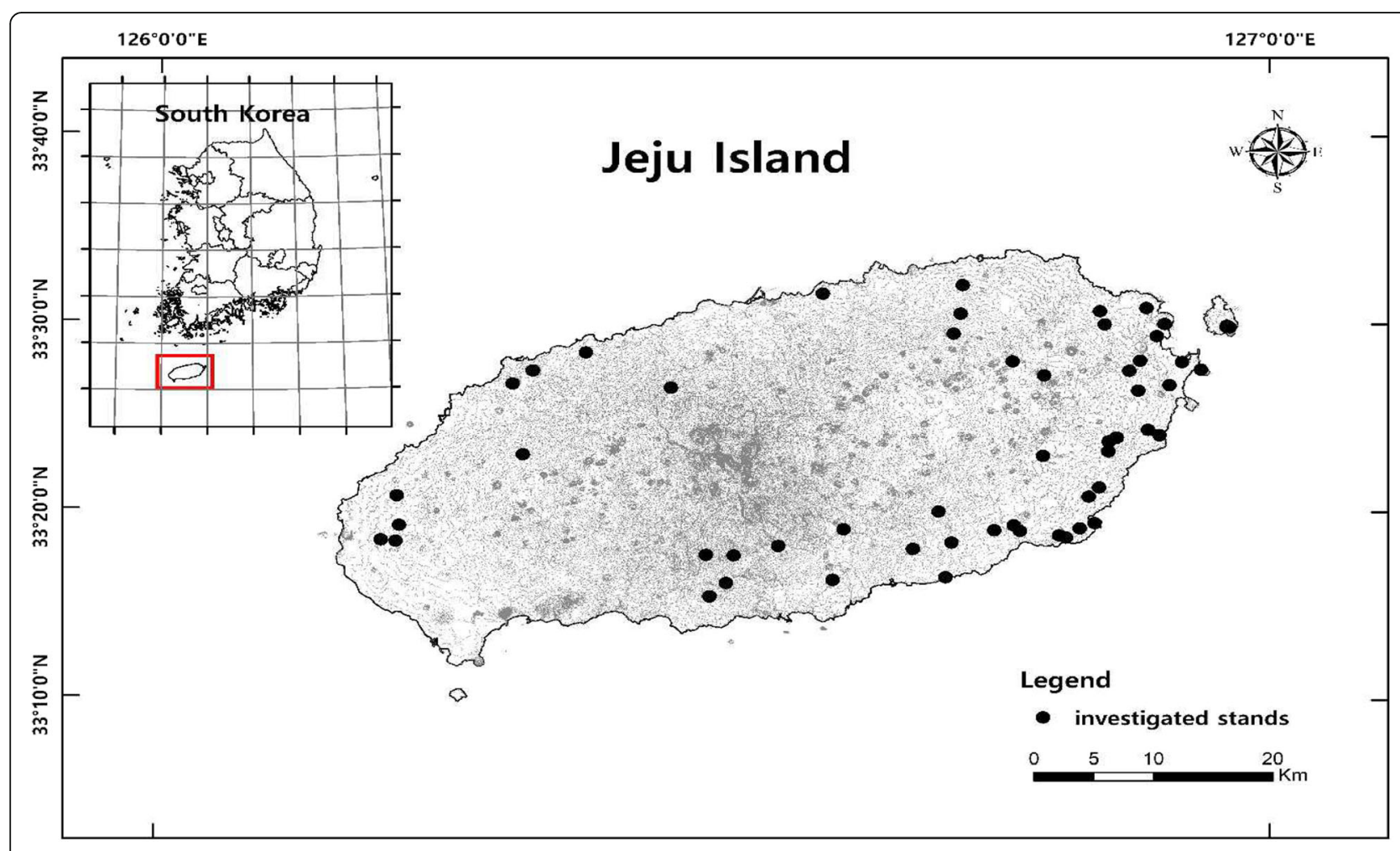

Fig. 1 Map showing the sites of $P$. thunbergii stands(alt. $\leq 500 \mathrm{~m}$ ) in Jeju Island 
factors such as the coordinates (GPS), altitudes above sea level, slope aspects, gradients, and the percentages of vegetation cover by tree crown layer were collected from each quadrat, and the percentages of tree crowns into tree layer were used forest gap of the environment variable.

To compare the relative dominance values of the tree species that appeared in each layer based on the vegetation survey data, the importance values (IV) were calculated by quantifying the quantitative (percentage of cover) and qualitative (frequency) data by tree species (Bray and Curtis 1957), and the relative import percentages obtained by integrating the IVs and converting the results into percentages were compared by layer (Brower and Zar 1977). In addition, to calculate the mean importance percentages (MIPs) applied with weights because the standing stocks of trees were different by layer, the relevant formula ((tree layer IV $\times 3+$ subtree layer IV $\times 2+$ shrub layer IV $\times 1) / 6$ ) was applied (Park 1985). The data were organized through an Excel program (Microsoft Office 2007) to create a vegetation data main matrix.

Plants were identified through Lee (2003a, 2003b), and when it was difficult to determine tree species, information such as photos, bark, and leaves was obtained to identify the tree species indoors. Scientific names, family names, and species names were indicated referring to the Korean Plant Names Index Committee (Korea National Arboretum 2017) presented and the national list of biological species (National Institute of Biological Resources 2018).

\section{Collection of environment variables}

In addition to the variables collected through field surveys, annual average temperatures and annual average precipitation, which are climate data, extracted from the 50 -year average climate data (1950-2000) provided by the (Worldclim-Global Climate Data 2019) (www.worldclim.org) at a resolution of 30 arc-seconds $\left(1 \mathrm{~km}^{2}\right)$ were used. In addition, straight-line distances between survey points and the coastline in the digital topographic map $(1: 25,000)$ were extracted using the Arcview 10.5 program and used to examine the effects of tidal winds on the distribution of trees.

\section{Multivariate statistical analysis}

Based on the organized data, TWINSPAN (Two-Way INdicator SPecies ANalysis), a sort of group analyses, was conducted. Since TWINSPAN is a classification process based on the data of all tree species (Hill and Gauch 1980), the group types in Pinus thunbergii forests were classified, and the layer structures, constituent tree species, and location environments of communities by type were indirectly identified through TWINSPAN (Sasaki et al. 2015).
In addition, a detrended canonical correspondence analysis (DCCA), which is an ordination analysis, was carried out to determine the relative distribution patterns based on the similarity of location environmental factors, including the species composition of the Pinus thunbergii stands for which the survey was conducted (Hill and Gauch 1980) with a view to identifying and more quantitatively and objectively analyzing those environmental factors that affect the group types. The multivariate statistical analysis as such was conducted through the PC-ORD6 software (McCune and Mefford 2006).

\section{Results and discussion}

Tree species constituting Pinus thunbergii forests and comparison of their importance values by layer

Major tree species surveyed in the Pinus thunbergii forests distributed in the lowlands of Jeju Island are as follows (Fig. 2). Out of the tree species that appeared, those with an appearance frequency lower than $10 \%$ were excluded. As a result, a total of 24 constituent tree species of 14 families were recorded in 56 survey plots. As for the numbers of species that appeared by layer, 7 species appeared in the tree layer, 11 species appeared in the subtree layer, 17 species appeared in the shrub layers, and 15 species appeared in the herb layer. Lauraceae showed the highest appearance frequency with a total of 5 species, and in the case of Theaceae and Fagaceae, 3 species each appeared. This was consistent with the report indicating that dominant species in evergreen broad-leaved forests in East Asia belong to Lauraceae, Theaceae, and Fagaceae and are mixed with needle-leaf trees (Fuziwara 1981). In addition, 2 species each of Moraceae and Ellaeagnaceae appeared and 1 species each of the remaining 9 families appeared (Fig. 3).

In order to determine the dominance values of the constituent tree species according to the layers of Pinus thunbergii forest, the importance values (IV) of the tree species by layer were calculated and compared (Table 1).

The tree layer is in the form of pure Pinus thunbergii forests because Pinus thunbergii exhibits an importance value of about $95 \%$ so that Pinus thunbergii can be regarded as a dominant tree species that forms most of the upper layer tree crowns. As for the importance values in the subtree layer, Pinus thunbergii (17.9) had the highest importance value, followed by Machilus thunbergii (14.9), Eurya japonica (14.5), Litsea japonica (13.7), and Neolitsea sericea (12.0). (Table 1). As for the importance values of tall evergreen broad-leaved trees among the constituent tree species, Machilus thunbergii (14.9) was the most predominant followed by Neolitsea sericea (12.0) and Cinnamomum japonicum (3.6), and the importance values of Machilus thunbergii and 


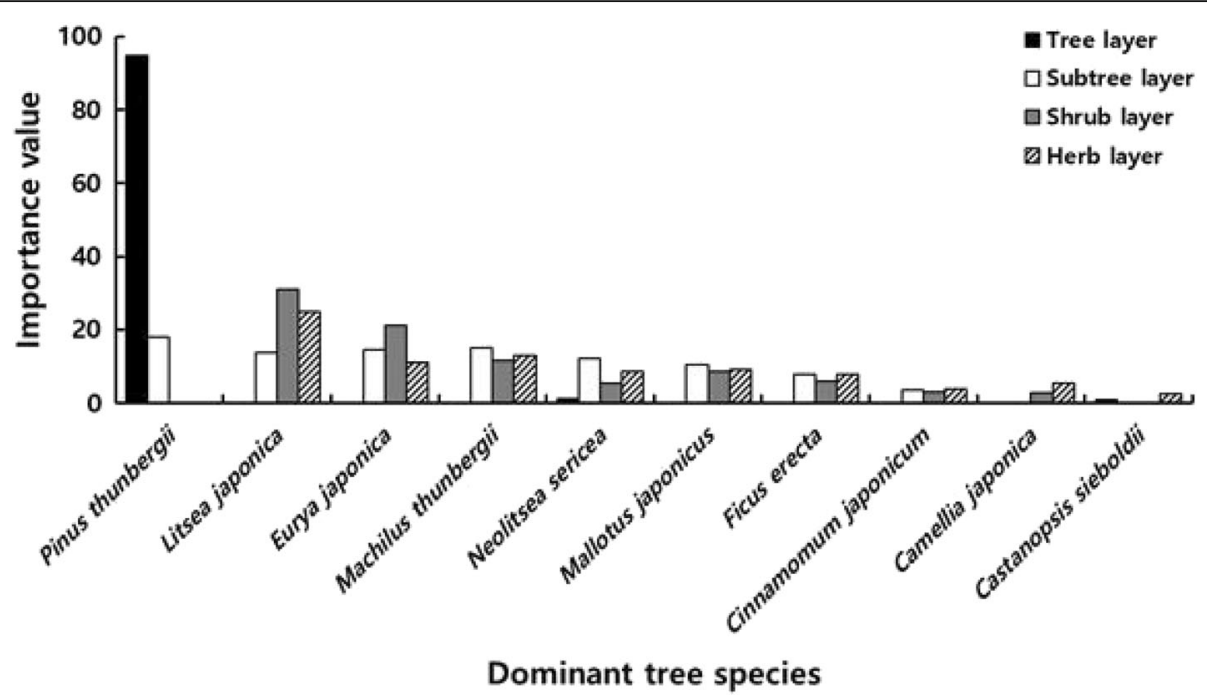

Fig. 2 The importance value of major tree species of $P$. thunbergii forest according to the stratification in the lowland of Jeju Island

Neolitsea sericea were not much different from the importance value of Pinus thunbergii (Table 1).

Pinus thunbergii did not appear in the shrub and herb layers. In the shrub layer, Litsea japonica (30.9) appeared the most frequently followed by Eurya japonica (21.0), Machilus thunbergii (11.4), Mallotus japonicus (8.6), and Ficus erecta Thunb. (5.9). In the herb layer, Litsea japonica (25.0) appeared the most frequently followed by Machilus thunbergii (12.8), Eurya japonica (11.0), Mallotus japonicus (9.0), and Neolitsea sericea (8.8). As for the distribution of tall evergreen broad-leaved trees, Machilus thunbergii was the most dominant followed by Neolitsea sericea and Cinnamomum japonicum in order of precedence identically to the subtree layer. This shows that evergreen broad-leaved trees are continuously supplemented so that the power of evergreen broadleaved trees will gradually increase in the understory vegetation. Therefore, it is considered that Pinus thunbergii will be gradually eliminated through competition with tall evergreen broad-leaved trees. In the herb layer, the seedlings and saplings of Castanopsis sieboldii, which was reported as a late-successional species (Oh and Choi 1993; Oh and Cho 1996; Tabata et al. 2015; Park et al. 2018), were frequently identified (Table 1).

The Pinus thunbergii forests are a vegetation degenerated by the destruction of the evergreen broad-leaved forests (Oh and Choi 1993; Oh and Kim 1996), and the Pinus thunbergii forests are considered to be succeeded by evergreen broadleaved trees such as Machilus thunbergii, Neolitsea sericea, Cinnamomum japonicum, and Castanopsis sieboldii (Yim

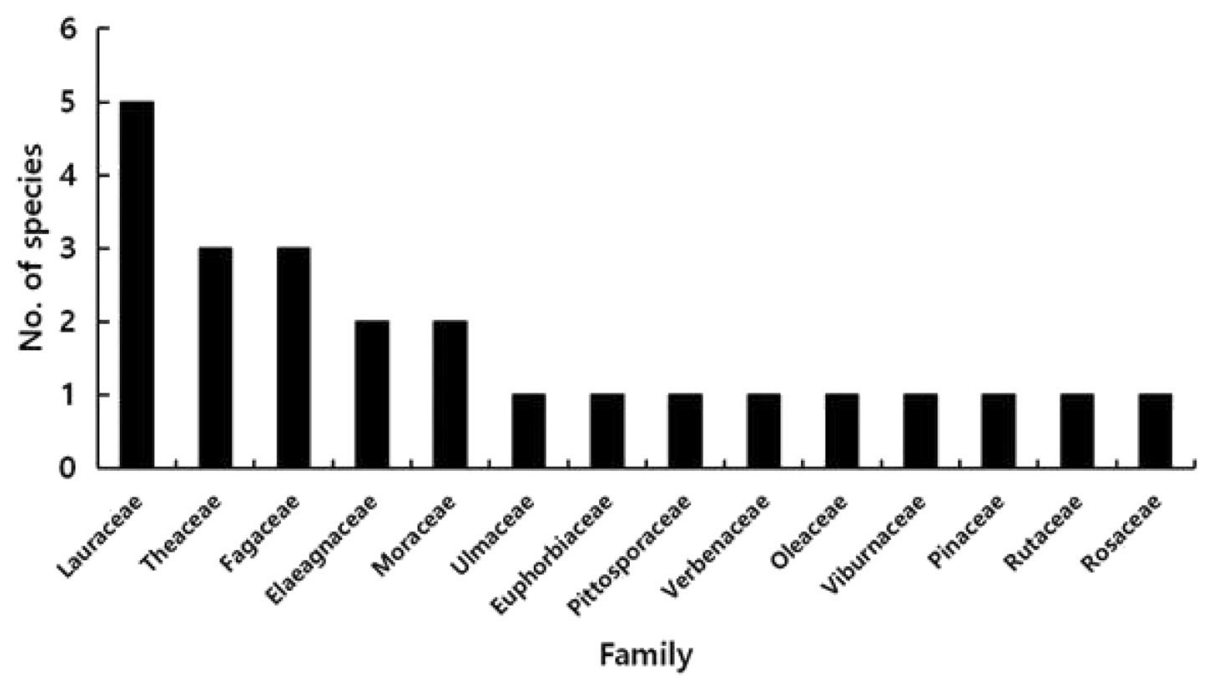

Fig. 3 Family-wise distribution of $P$. thunbergii forest in the lowland of Jeju Island 
Table 1 The importance value (IV) of major tree species according to the layers of $P$. thunbergii forest

\begin{tabular}{|c|c|c|c|c|c|c|}
\hline \multirow[t]{2}{*}{ Species } & \multirow[t]{2}{*}{ Korean name } & \multicolumn{4}{|l|}{ Layer } & \multirow[t]{2}{*}{ RIV } \\
\hline & & Tree & Subtree & Shrub & Herb & \\
\hline Pinus thunbergii & & 94.72 & 17.89 & - & - & 48.00 \\
\hline Litsea japonica & & - & 13.70 & 30.88 & 24.98 & 11.55 \\
\hline Eurya japonica Thunb. & & - & 14.49 & 21.07 & 11.00 & 8.35 \\
\hline Machilus thunbergii & & - & 14.91 & 11.44 & 12.83 & 7.26 \\
\hline Neolitsea sericea & & 1.25 & 12.00 & 5.58 & 8.77 & 5.66 \\
\hline Mallotus japonicus & & - & 10.53 & 8.62 & 9.08 & 4.21 \\
\hline Ficus erecta & & - & 7.75 & 5.89 & 7.93 & 3.94 \\
\hline Cinnamomum japonicum & & - & 3.57 & 3.14 & 3.90 & 1.91 \\
\hline Camellia japonica & & - & - & 2.83 & 5.54 & 0.77 \\
\hline Quercus glauca & & 1.52 & - & - & - & 0.70 \\
\hline Castanopsis cuspidata & & 0.80 & - & - & 2.40 & 0.70 \\
\hline Celtis sinensis & & 0.37 & 0.37 & 1.23 & - & 0.45 \\
\hline Viburnum odoratissimum & & - & - & - & 1.32 & 0.18 \\
\hline Lindera erythrocarpa & & - & - & - & 1.11 & 0.15 \\
\hline Others & & 1.34 & 4.79 & 9.32 & 11.14 & 6.17 \\
\hline
\end{tabular}

et al. 1990), which are expected to be the main tree species in the potential natural vegetation (PNV). In addition, the number of species appeared was smaller than that of Pinus thunbergii forests in Jeju Island reported by Park et al. (2013), and the differences were also shown in species compositions by layers. This is attributable to the fact that the survey in this study was conducted in intact Pinus thunbergii forests with relatively fewer external disturbances in lowlands at altitudes below $500 \mathrm{~m}$ above sea level, and dominant species were mainly written considering appearance frequencies.

\section{Classification of groups in Pinus thunbergii forests (TWINSPAN)}

TWINSPAN was carried out using quantitative data on 24 species that appeared in the 56 stands in total. As a result, the 24 species were largely divided into 4 groups (I, II, III, IV) at level 2 (Fig. 4). At level 1, the amount of information was 0.2955 as an eigenvalue, and the species were largely divided into 2 groups by the indicator species Litsea japonica (-), Machilus thunbergii (-), and Eurya japonica (+). At level 2, the amount of information for some species was 0.2300 as an eigenvalue, and these species were divided into group I and group II by the indicator species Eurya japonica (+) and Neolitsea sericea $(+)$; the amount of information for the remaining species was 0.3211 as an eigenvalue, and these species were divided into group III and group IV by the indicator species Litsea japonica (-) and Neolitsea sericea (+).

The group classification by TWINSPAN was reported to be made with environmental factors such as the

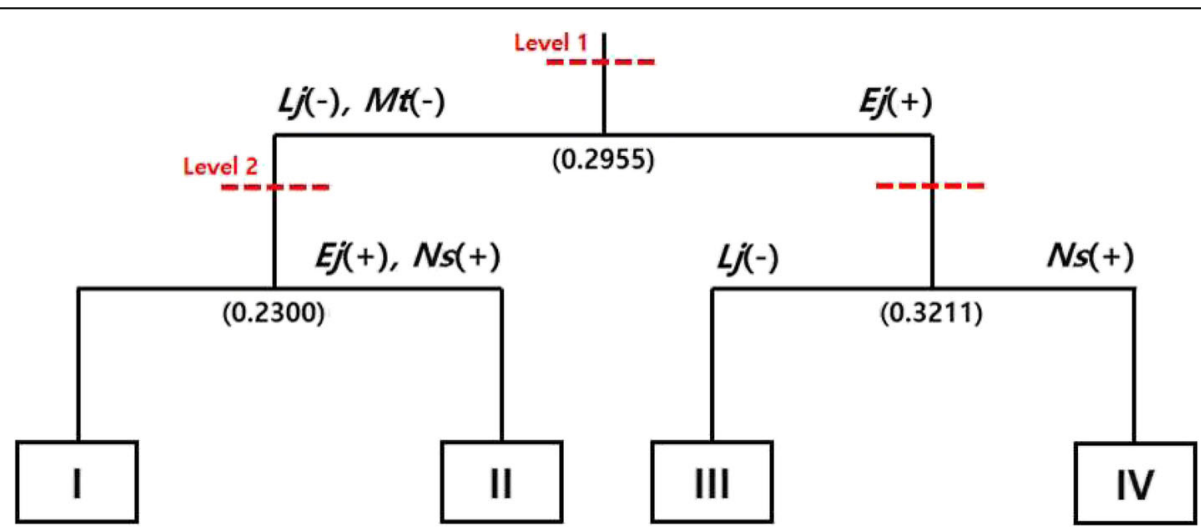

Fig. 4 The pathway of subdivision into groupings of $P$. thunbergii stands by using TWINSPAN, which used importance value of tree species of the total layer. The abbreviations in both sides of pathway indicate indicator species, the numbers under the line, the eigenvalues for the division ( $L j$, Litsea Japonica; Mt, Machilus thunbergii; Ej, Eurya japonica; Ns, neolitsea sericea) 
presence of specific species, altitudes above sea level, and soil humidity (Taylor et al. 1987; Huang and Moral 1988; Lee et al. 1990a; Lee et al. 1990b; Lee et al. 1991; Lee et al. 1992), aspects (Lee et al. 1990b), and forest fires (Allen and Partridage 1988). However, since the Pinus thunbergii forests surveyed in this study were limited to those at altitudes lower than $500 \mathrm{~m}$ above sea level and the growth environments of the constituent tree species were similar such as areas adjacent to the coast and alluvial lands where the water environment was relatively stable (Fuziwara 1981; Oh and Kim 1996; Choi 2012), the tendency of group separation by certain environmental factors was not clear. However, given the location environments of the classified species, altitudes above sea level are assumed to have the largest effect leading to the classification of groups by the heterogeneous spatial distributions derived from altitudes above sea level (Lee and Cho 2000).

The results of the analysis of the constituent tree species by group and the dominant tree species by layer through TWINSPAN are as follows. Since the survey was conducted in intact Pinus thunbergii forests, Pinus thunbergii was the most dominant in all groups (I IV), and the tree layers by group showed high importance values (IV) to the extent that they showed the forms of pure Pinus thunbergii forests (Fig. 5). However, in the case of the subtree layer, shrub layer, and herb layer, which were understory vegetation, importance values (IV) by tree species were different. Considering the foregoing, individual groups were named based on the tree species that showed high importance values among at least subtree species, which constituted the understory vegetation, except for Pinus thunbergii, so individual groups were named as follows: Litsea japonica-Machilus thunbergii group (group I), Eurya japonica-Machilus thunbergii group (group II), Eurya japonica-Ficus erecta Thunb. group (group III), and Eurya japonica-Neolitsea sericea group (group IV).

Litsea japonica-Machilus thunbergii group (group I) appeared in 31 stands and comprised a total of 20 species. The relative import value (RIV) was the highest in the case of Pinus thunbergii (49.7), followed by Litsea japonica (19.3), Machilus thunbergii (9.5), Mallotus japonicus (5.4), Ficus erecta Thunb. (3.7), and Neolitsea sericea (3.6).

In addition to the tree layer, Pinus thunbergii had the highest importance value in the subtree layer too but did not appear in the shrub and herb layers. Litsea japonica, which is a sub-tall evergreen broad-leaved tree, showed the highest importance value (IV) in the understory vegetation and was distributed in mixture with tall evergreen broad-leaved trees such as Machilus thunbergii and Neolitsea sericea and deciduous broad-leaved trees such as Mallotus japonicus and Ficus erecta Thunb.

The foregoing was identical to the species composition in the process of secondary succession appearing in the fallow fields in the lowlands of Jeju Island (You and Lee 2003), and Pinus thunbergii is considered to be gradually
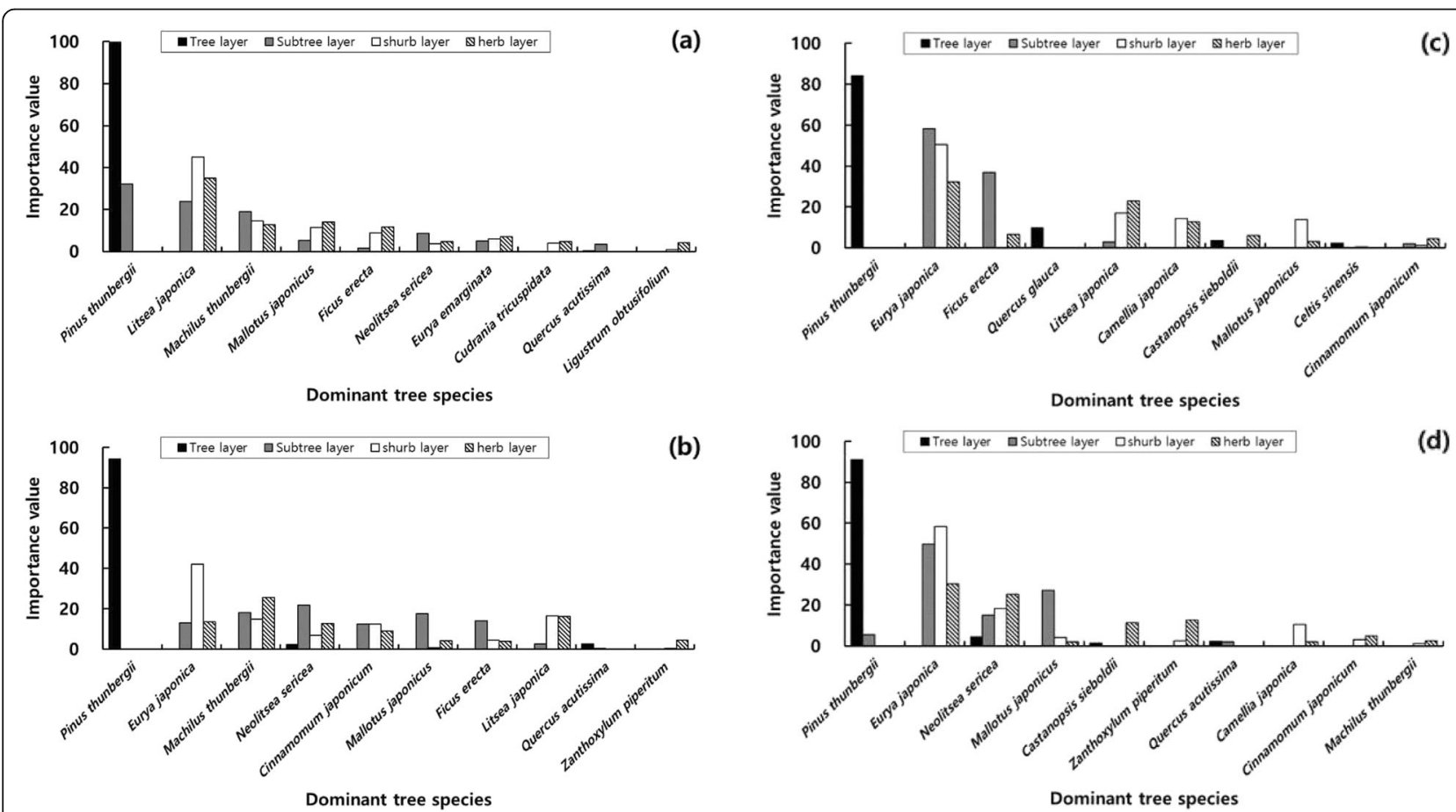

Fig. 5 The importance values of major tree species of each layer of groups separated by TWINSPAN (a group I, b group II, c group III, d group IV) 
eliminated due to the lack of successional trees and competition with evergreen broad-leaved trees such as Litsea japonica, Machilus thunbergii, and Neolitsea sericea. In addition, the appearance of deciduous broadleaved trees such as Mallotus japonicus and Ficus erecta Thunb. is considered attributable to the effect of artificial interference due to the low altitudes above sea level.

The Eurya japonica-Machilus thunbergii group (group II) appeared in 11 stands and comprised a total of 20 species. The importance value (RIV) was the highest in the case of Pinus thunbergii (43.9) followed by Eurya japonica (10.8), Machilus thunbergii (10.2), Neolitsea sericea (9.6), and Cinnamomum japonicum (6.2). However, Pinus thunbergii appeared only in the tree layer that constitutes the upper tree crown and did not appear in the understory vegetation.

Understory vegetation was dominated by Eurya japonica, Machilus thunbergii, Neolitsea sericea, and Cinnamomum japonicum, which are evergreen broad-leaved trees. In particular, all of Machilus thunbergii, Neolitsea sericea, and Cinnamomum japonicum, which are representative tall tree species in warm temperate evergreen broad-leaved forests, showed a tendency to have high importance values (IV) in all layers indicating that the power of these evergreen broad-leaved trees will become larger later.

Oh and Choi (1993), who reported the vegetation succession stage of evergreen broad-leaved forests, regarded Machilus thunbergii and Neolitsea sericea as the tree species in the highest stage, Oh and Kim (1996) regarded Neolitsea sericea and Cinnamomum japonicum as the tree species in the highest stage, and Park et al. (2018) reported Machilus thunbergii, Neolitsea sericea, and Cinnamomum japonicum as the tree species in the intermediate stage. As such, this group is considered to be in the progress of succession from the Pinus thunbergii forests to evergreen broad-leaved forests. In other words, green evergreen broad-leaved trees, which are shade trees, will gradually become more dominant through continuous replenishment while continue to be replenished, and Pinus thunbergii, which is sun trees, will be eliminated due to competition with evergreen broadleaved tree and the lack of successor trees.

The Eurya japonica-Ficus erecta Thunb. group (group III) appeared in 7 stands and comprised a total of 18 species. The relative import value (RIV) was the highest in the case of Pinus thunbergii (47.6), followed by Eurya japonica (21.0), Ficus erecta Thunb. (7.4), Quercus glauca Thunb. (5.6), Litsea japonica (5.5), Camellia japonica (3.5), and Castanopsis sieboldii (2.8).

In this group, the importance value in the tree layer was the highest in the case of Pinus thunbergii, followed by tall evergreen broad-leaved trees such as Quercus glauca Thunb. and Castanopsis sieboldii. This suggests that the remaining evergreen broad-leaved tree forests are succeeded by secondary forests due to anthropogenic disturbances (Tabata et al. 2015). Quercus glauca Thunb. has been reported to grow in collapsed slopes, unstable soils (Hoshi et al. 1998), exposed rock areas, and barren areas (Miyawaki 1981), and Castanopsis sieboldii has been reported to mainly develop in the deforested and damaged areas of warm temperate evergreen broadleaved forests (Han et al. 2004).

Eurya japonica is a dominant species that shows the highest importance value (VI) in the understory vegetation. It is distributed in mixture with Ficus erecta Thunb. in the subtree layer and in mixture with Litsea japonica, Camellia japonica, and Mallotus japonicus in the shrub and herb layers. The appearance of the deciduous broadleaved trees such as Mallotus japonicus and Ficus erecta Thunb. is judged to be due to the effect of artificial interferences because of the low altitude above sea level.

Han et al. (2004) reported that the succession stage of the grazing grasslands in the lowlands of Jeju Island will progress from climbing pioneer plants to Eurya japonica, Camellia japonica, and Quercus glauca Thunb. and then to Quercus glauca Thunb. and Castanopsis sieboldii, which were in existing remaining forests. Since Quercus glauca Thunb. and Castanopsis sieboldii are intermediate-stage tree species in the succession stage to evergreen broad-leaved forests and can be commonly seen in secondary forests (Oh and Choi 1993; Oh and Cho 1996; Tabata et al. 2015), this group is considered to belong to an intermediate stage in the succession stage.

The Eurya japonica-Neolitsea sericea group (group IV) appeared in 7 stands and comprised a total of 16 species. The relative import value (RIV) was the highest in the case of Pinus thunbergii (48.9) followed by Eurya japonica (22.2), Neolitsea sericea (11.4), Mallotus japonicus (6.7), and Castanopsis sieboldii (2.3).

Neolitsea sericea, which was reported as the highest stage tree species in warm temperate evergreen broadleaved forests because of its high shade tolerance and interspecies competitiveness (Oh and Choi 1993; Oh and Cho 1996), is considered to become the most dominant in this group later because it is distributed at importance values (IV) in the form of an inverted J in all layers. The importance values of tall evergreen broad-leaved trees such as Neolitsea sericea, Castanopsis sieboldii, Cinnamomum japonicum, and Machilus thunbergii were shown to be high in the herb layer. This indicates that the evergreen broad-leaved trees will become more dominant hereafter to compete with Pinus thunbergii later. Neolitsea sericea will be locally dominant in wet and fertile stony areas, while Machilus thunbergii and Cinnamomum japonicum will be locally dominant in fertile lowlands with deep soils ( $\mathrm{Oh}$ and Choi 1993). 
In particular, Castanopsis sieboldii, which is correlated with altitudes above sea level (Iehara et al. 1983), is an evergreen broad-leaved tree species at an intermediate stage (Oh and Choi 1993; Oh and Cho 1996; Tabata et al. 2015) or at the highest stage in the succession stage (Park et al. 2018), and Eurya japonica, which is a subtree that is the most dominant in the understory vegetation, has been reported as a tree species at an intermediate stage (Oh and Choi 1993). Therefore, this group is in the process of succession into evergreen broad-leaved forests and is judged to be at an intermediate stage in the succession stage.

\section{Ordination of Pinus thunbergii forests}

DCCA analysis was carried out, and as a result, the eigenvalues were 0.3139 for the first axis and 0.1729 for the second axis, and 56 stands were arranged on their respective coordinate axes according to their amounts of information (Fig. 6).

This was generally similar to the trend of group classification by TWINSPAN (groups I to IV). Group I was located on the left of the first axis, group II on the center, and stands of group III and group IV on the right. The stands distributed adjacent to each other show similarity in species compositions and vegetation structures, eventually reflecting the location environments. That is, some stands of each group were closely located at the center. This is considered attributable to the fact that Pinus thunbergii was commonly the most dominant in the upper layer vegetation.

The species compositions of several stands (p26, p54, and p55) located far from the central value of each group were different from those of other stands. These stands were in the state of retrogressive succession with relatively high importance values of deciduous broadleaved trees because parts of Pinus thunbergii forests were destroyed due to artificial interference or in the state of substitute vegetation where some evergreen broad-leaved trees remained.

The eigenvalue (standard deviation (SD)) of beta diversity (Kimmins 1987), which is a variation in species compositions between two groups of which the location

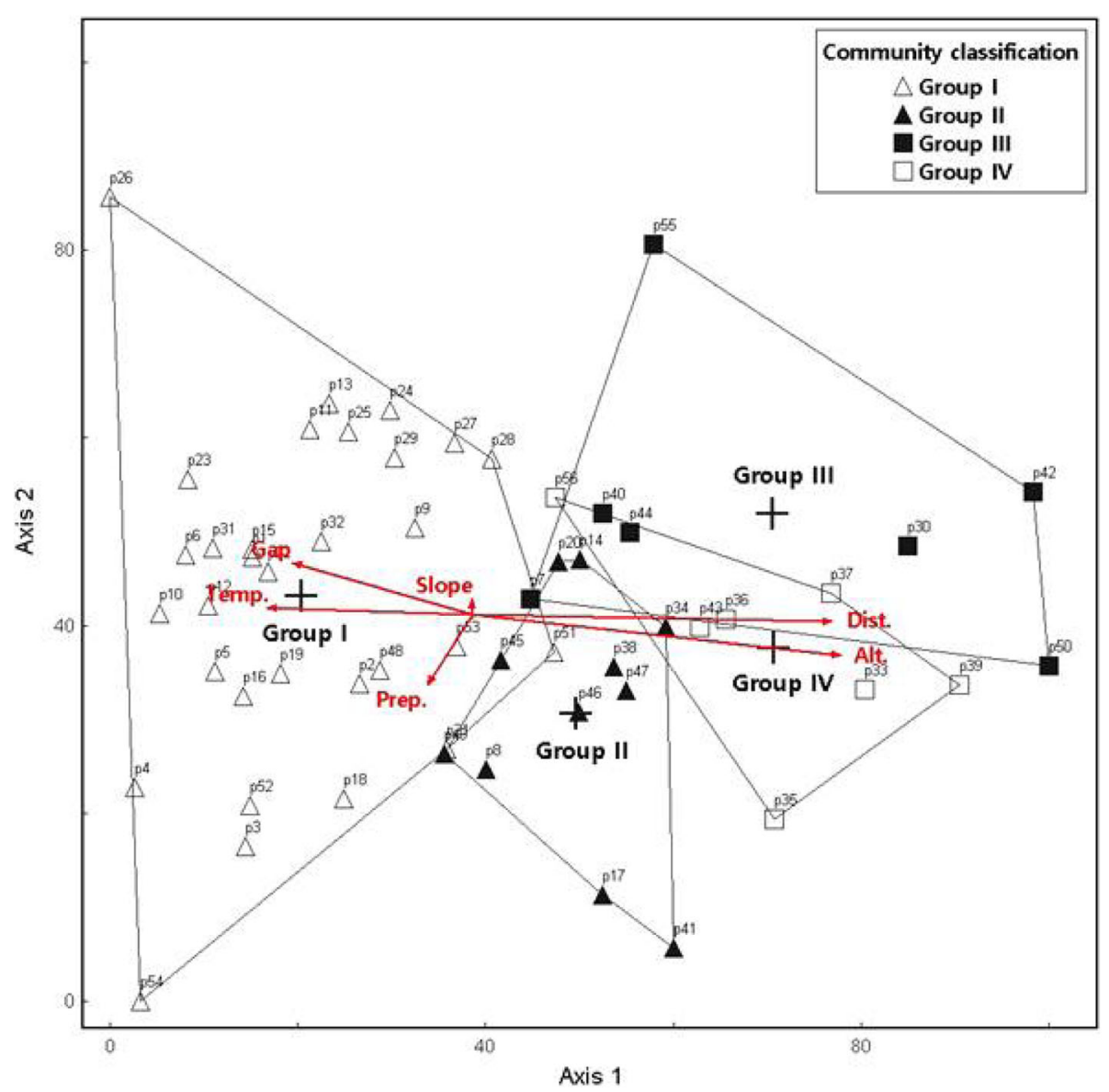

Fig. 6 DCCA ordination plot between major groups and environmental variables. The environmental variables are altitude (Alt.), distance from shore (Dist.), annual mean temperature (Temp.), forest gap, annual mean precipitation (Prep.), and slope. Four shapes are the main groups separated by TWINSPAN, and cross shape shows centroids of each group 
environments were adjacent to each other, was shown to be 2.94. The closer the eigenvalue is to 4.0 , the more completely the groups were differentiated so that the trend of succession trend can be predicted (Gauch and Whittaker 1972). However, this eigenvalue is lower compared to previous studies conducted by diverse research centers (Olsvig-Whittaker et al. 1983; Bernard et al. 1985; Westman 1985). That is, it is considered that the Pinus thunbergii forests in the lowlands of Jeju Island are in the process of succession into evergreen broadleaved forests, which are a potential natural vegetation, and the evergreen broad-leaved trees are considered to be at an intermediate stage, an immature stage, in the succession stage.

In addition, through the DCCA analysis, altitudes, distances from the coast, annual average temperatures, forest gaps, annual average precipitation, and gradients were identified as major environmental factors that affect the distribution of stands. This was consistent with the report indicating that the distributions of evergreen broad-leaved forests are divided according to the distances from the coast and temperatures (Hattori 1992; Hattori et al. 2008). However, these environmental factors did not play any role in the grouping of the stands because the location environments of even those individual groups that seem to be relatively homogeneous exhibit heterogeneous spatial distributions due to their correlations with diverse environmental factors (Lee and Cho 2000).

Park et al. (2018) regarded climates (temperature, precipitation, etc.) and soil conditions as important environmental factors that affect the vegetation succession and development of evergreen broad-leaved trees. In this study, however, attempts were made to investigate the correlations between evergreen broad-leaved trees and environmental factors centering on the biological and non-biological factors recorded during field surveys.

The major stands of group I distributed from the left to center of the first axis showed tendency form groups while showing strong positive $(+)$ correlations with temperatures and forest gaps. However, the stands of group II group IV showed positive correlations with altitudes above sea level and distances from the coast but did not form any group. That is, under the effects of environmental factors conflicting with each other, the distributions of the constituent tree species were largely divided into two patterns, and the representative evergreen broad-leaved tree species in the understory vegetation were Litsea japonica, Machilus thunbergii, Neolitsea sericea, and Castanopsis sieboldii in group I and Eurya japonica, Machilus thunbergii, Neolitsea sericea, and Castanopsis sieboldii in groups II IV. In addition, the stands distributed at the lower left of group I and the group II stands based on the second axis showed positive $(+)$ correlations with annual average precipitation, and the representative constituent species of the understory vegetation was Machilus thunbergii, a tall evergreen broad-leaved tree.

The correlations between major evergreen broad-leaved tree species that constitute the Pinus thunbergii forests and environmental factors found through the DCCA analysis are as follows (Fig. 7). Pinus thunbergii showed no statistically significant correlation with environmental factors. This is because Pinus thunbergii is an afforestation tree species planted on a large scale in the mountains and coastal areas of Jeju Island at altitudes lower $500 \mathrm{~m}$ because it grows rapidly at the beginning and is strong against salt damage (National Institute of Forest Science 2013). However, the major evergreen broad-leaved tree species that constitute the understory vegetation showed correlations with environmental factors.

Litsea japonica, which is a subtree species, was distributed in areas where annual average temperatures are high and the tree crown layer is opened highly, and Eurya japonica was distributed in areas at relatively high altitudes above sea level that are not coastal areas but are relatively close to mountainous areas. Litsea japonica is a species that appears in the lowlands of Jeju Island with large amounts of light at the beginning of secondary succession (You and Lee 2003). Cheon et al. (2012) reported that Litsea japonica grows while appropriately adapting itself to a wide range of light shading of 3595\%. Given that Litsea japonica showed high dominance in the understory vegetation of all groups (I, II, III) except for group IV, its seedlings and saplings can adapt well to changing light environments, and appropriate location environments for its growth are lowlands at altitudes of about $200 \mathrm{~m}$ above sea level where the annual average temperature is $15^{\circ} \mathrm{C}$ (Table 2).

Among the tall tree species, Machilus thunbergii was distributed in areas adjacent to the coast where annual average temperatures, and annual average precipitation are high and altitudes above sea level are low; Neolitsea sericea and Cinnamomum japonicum were distributed in areas in the middle between the coast and mountainous areas where altitudes above sea level are relatively high; and Castanopsis sieboldii was distributed in areas at high altitudes above sea level, which is far from the coast.

The ecological statuses of Machilus thunbergii, Neolitsea sericea, and Cinnamomum japonicum, which are representative tall tree species of in warm temperate evergreen broad-leaved forests, are similar (Hattori 1993). This could be identified in domestic previous studies indicating that these tree species were frequently distributed in mixture (Oh and Kim 1996; Choi 2012) and the understory vegetation of group I and group II in this study. However, on reviewing the main environmental factors of group I in which Machilus thunbergii is 


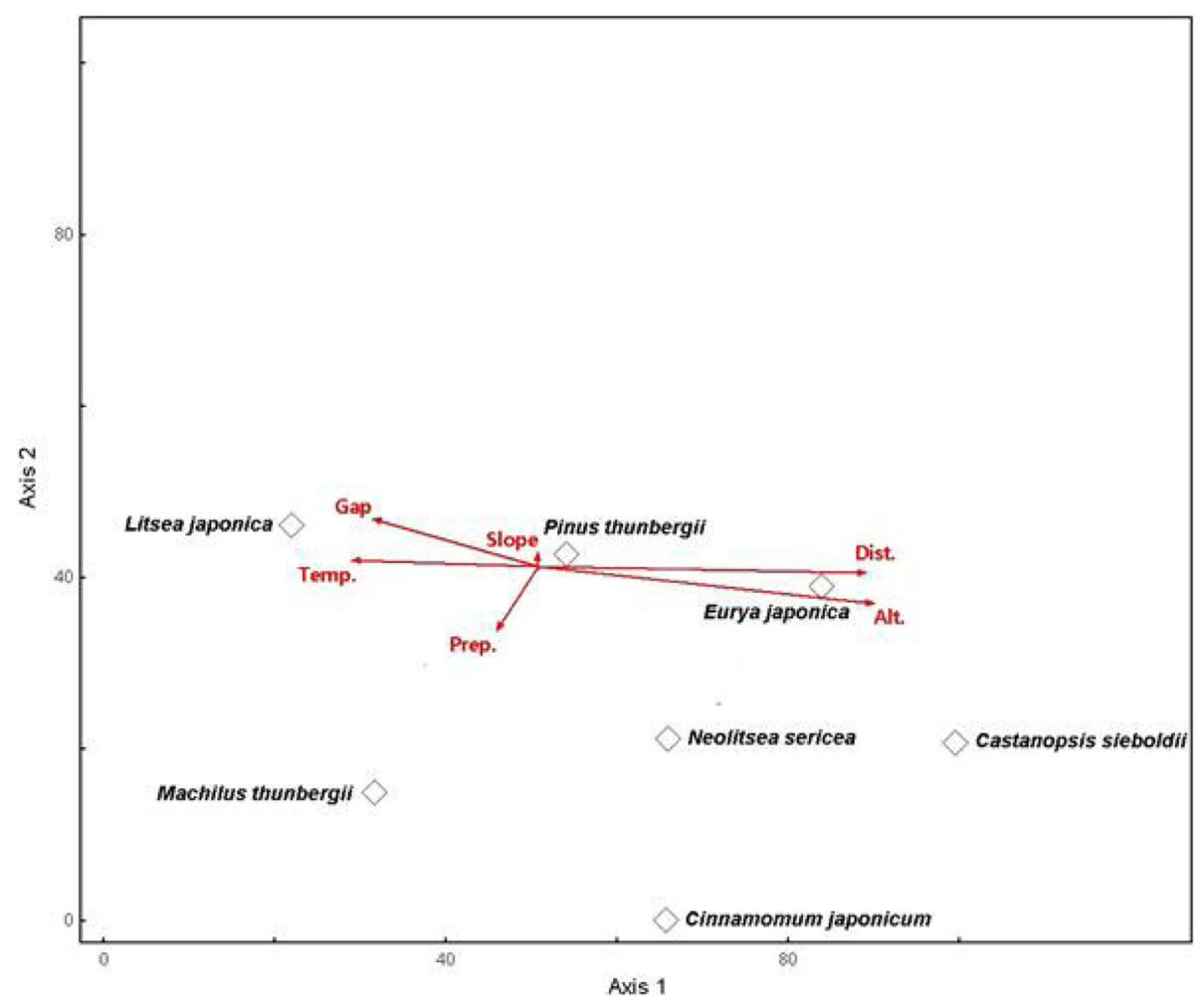

Fig. 7 DCCA ordination plot between major tree species and environmental variables. The environmental variables are altitude (Alt.), distance from shore (Dist.), annual mean temperature (Temp.), forest gap, annual mean precipitation (Prep.), and slope

dominant in the understory vegetation and group IV in which Neolitsea sericea is dominant in the understory vegetation (Table 2), it can be seen that the distributions of the stands are clearly divided by altitudes above sea level, distances from the coast, and annual average temperatures.

Based on the temperature range of the average monthly temperatures in the coldest month, Hattori (1993) reported that the growth and distribution areas of Machilus thunbergii appeared in mild climates with average temperatures in a range of 1 to $11^{\circ} \mathrm{C}$ and those of Neolitsea sericea appeared in a relatively low temperature range of 1.3 to $5.3^{\circ} \mathrm{C}$. As can be seen in Table 2, the annual average temperatures of groups I and II and group IV showed a difference of $1{ }^{\circ} \mathrm{C}$ on average, and clear differences between the two groups could be also identified from the difference in altitudes above sea level and distances from the coast.

That is, whereas group I and group II in which Machilus thunbergii is dominant in the understory vegetation were affected by warm and moist oceanic climates throughout the year because they were distributed in lowland coastal areas at altitudes of about $200 \mathrm{~m}$ above sea level, group IV in which Neolitsea sericea is dominant in the understory vegetation was not much affected by oceanic climates because it was distributed in areas where altitude above sea level was relatively high (at least about $350 \mathrm{~m}$ ) that were far from the coastal areas among the survey areas. Given the area where the Neolitsea sericea group grows naturally in Bulgapsan Mountain, Jeonnam, South Korea, reported by $\mathrm{Oh}$ and Jee (1995), among evergreen broad-leaved tree species,

Table 2 Average value and standard deviation of major environmental factors in each group

\begin{tabular}{lllllll}
\hline Group & Altitude $(\mathrm{m})$ & $\begin{array}{l}\text { Distance from } \\
\text { coast }(\mathrm{m})\end{array}$ & $\begin{array}{l}\text { Annual mean } \\
\text { temperature }\left({ }^{\circ} \mathrm{C}\right)\end{array}$ & $\begin{array}{l}\text { Annual mean } \\
\text { precipitation }(\mathrm{mm})\end{array}$ & Slope (degree) & Canopy gap (\%) \\
\hline I & $74.3 \pm 0.3$ & $1460.9 \pm 1254.2$ & $15.0 \pm 0.3$ & $1659.2 \pm 227.2$ & $8.5 \pm 8.3$ & $46.1 \pm 39.9$ \\
II & $125.2 \pm 52.0$ & $3822.9 \pm 2801.5$ & $15.0 \pm 0.4$ & $1747.0 \pm 65.0$ & $12.8 \pm 9.0$ & $15.5 \pm 10.1$ \\
III & $142.7 \pm 108.1$ & $4302.6 \pm 2902.5$ & $14.8 \pm 0.5$ & $1605.6 \pm 224.6$ & $7.1 \pm 8.5$ & $16.4 \pm 8.0$ \\
IV & $365.0 \pm 108.3$ & $6061.1 \pm 1287.5$ & $14.0 \pm 0.5$ & $1616.1 \pm 107.9$ & $10.4 \pm 8.5$ & $23.6 \pm 8.5$ \\
Grand mean & $129.2 \pm 112.1$ & $2855.1 \pm 2498.5$ & $14.9 \pm 0.5$ & $1664.4 \pm 194.5$ & $9.4 \pm 8.5$ & $33.6 \pm 33.3$ \\
\hline
\end{tabular}


Neolitsea sericea is judged to be able to grow in lowtemperature areas where temperatures are relatively low.

However, in group II, Neolitsea sericea showed the highest importance value next to Machilus thunbergii. These two tree species live in mixture with each other at high appearance frequencies because both tree species have a high tolerance to tidal winds and salts (Hattori 1993), and the high importance values of them are judged to be maintained through the intake of their fruits by birds. In particular, brown-eared bulbuls are not seed predators that crush fruit and seeds to eat (Moermond and Denslow 1985) but are seed spreaders that swallow the whole fruits to move the seeds (Kim et al. 2002; Choi and Chae 2007; Cho et al. 2011; Kim et al. 2015), and Kim et al. (2015) reported that the seeds of Machilus thunbergii and Neolitsea sericea were spread through the fruit intake by brown-eared bulbuls.

In addition, it has been reported that in the case of Machilus thunbergii, an annual average precipitation level of $1600 \mathrm{~mm}$ is a distribution limit condition (Miyawaki 1980) because the distribution is strictly limited in dry climates since the seedlings wither to death (Hattori et al. 2008). For all groups (I to IV), the mean values of annual average precipitation levels were above the distribution limit condition $1600 \mathrm{~mm}$ (Table 2). In particular, given that the importance values of Machilus thunbergii were shown to be high in the understory vegetation of those stands that were included in groups I and II, which showed positive $(+)$ correlations with annual average precipitation during DCCA analysis, alluvial land sites or the lower part of lowland slopes are considered to be prerequisites for the growth of Machilus thunbergii.

\section{Conclusion}

The Pinus thunbergii forests in Jeju Island are representative evergreen needle-leaf tree forests planted in lowlands along the coastline and are actual vegetation. Virtue vegetation refers to the vegetation that is assumed to have been in the past, and potential natural vegetation refers to the vegetation that may be formed in the area if anthropogenic disturbance disappears (Barbour et al. 2015). Primeval forests and natural forests in Japan (Miyawaki 1980, Miyawaki 1981; Ishida et al. 2005; Kuroda et al. 2015) and southeastern China (Song and Da 2016) that belong to the same warm temperate evergreen broad-leaved forest zone and are neighboring countries in East Asia influenced by monsoon climates are reported as evergreen broad-leaved forests, and since evergreen broad-leaved trees appear very frequently in the understory vegetation surveyed in this study, the virgin vegetation and potential natural vegetation in Jeju Island are judged as evergreen broad-leaved forests.

Previous studies that reported trends of succession toward evergreen broad-leaved forests in island areas in the southern part of South Korea (Oh and Choi 1993; Oh and Kim 1996; Park et al. 2018), fallow fields in the lowlands of Jeju Island (You and Lee 2003) and grazing grasslands (Han et al. 2004) and major evergreen broadleaved trees that constitute the understory vegetation found in this study were put together to estimate rough vegetation succession stage as shown in Fig. 8. Among the community types classified in succession stage, Litsea japonica-Mallotus japonicus community, Eurya japonica-Mallotus japonicus community, and Eurya japonica-Neolitsea sericea community had less influence of anthropogenic factors which is causing retrogressive succession. These communities were intact forests with few disturbances which was the development of lowland, logging caused by pine wilt disease, and afforestation (Taoda 1988). The secondary succession of Pinus thunbergii forests in the lowlands of Jeju Island will be progressed in different ways depending on the location environment factors; Pinus thunbergii (early successional species) that is not supplemented by seedling and sapling in all Pinus thunbergii communities will be declined in the long term.

The secondary succession stage in those lowlands (altitudes below $100 \mathrm{~m}$ ) that are close to the coast where the climates are mild and tidal winds are strong will progress from Pinus thunbergii (early successional species) to Machilus thunbergii and Litsea japonica (mid-successional species) and then to Machilus thunbergii (latesuccessional species).

The importance value of Litsea japonica which is a subtree species was the highest in the understory vegetation, but in the long run, it will be dominated by Machilus thunbergii which is tree species. Mallotus japonicus which is a deciduous subtree species with inverted J shape in the understory vegetation is expected to be consistently supplemented by seedling and sapling; this is considered to be because this community is continuously affected by human interference in the lowlands (You and Lee 2003). The secondary succession stage in those lowlands (altitudes about 100 250 m) in the middle between the coast and mountainous areas where precipitation is rich will progress from Pinus thunbergii (early successional species) to Machilus thunbergii, Neolitsea sericea, Cinnamomum japonicum, Eurya japonica, and Litsea japonica (mid-successional species) and then to Machilus thunbergii and Neolitsea sericea (late-successional species).

Importance value of Machilus thunbergii, Neolitsea sericea, and Cinnamomum japonicum was high in understory vegetation, and these evergreen broad-leaved trees that are supplemented by seedling and sapling will be dominated in the long term. And Eurya japonica and Litsea japonica that is a shrub and subtree in life from will be dominated in the understory. 


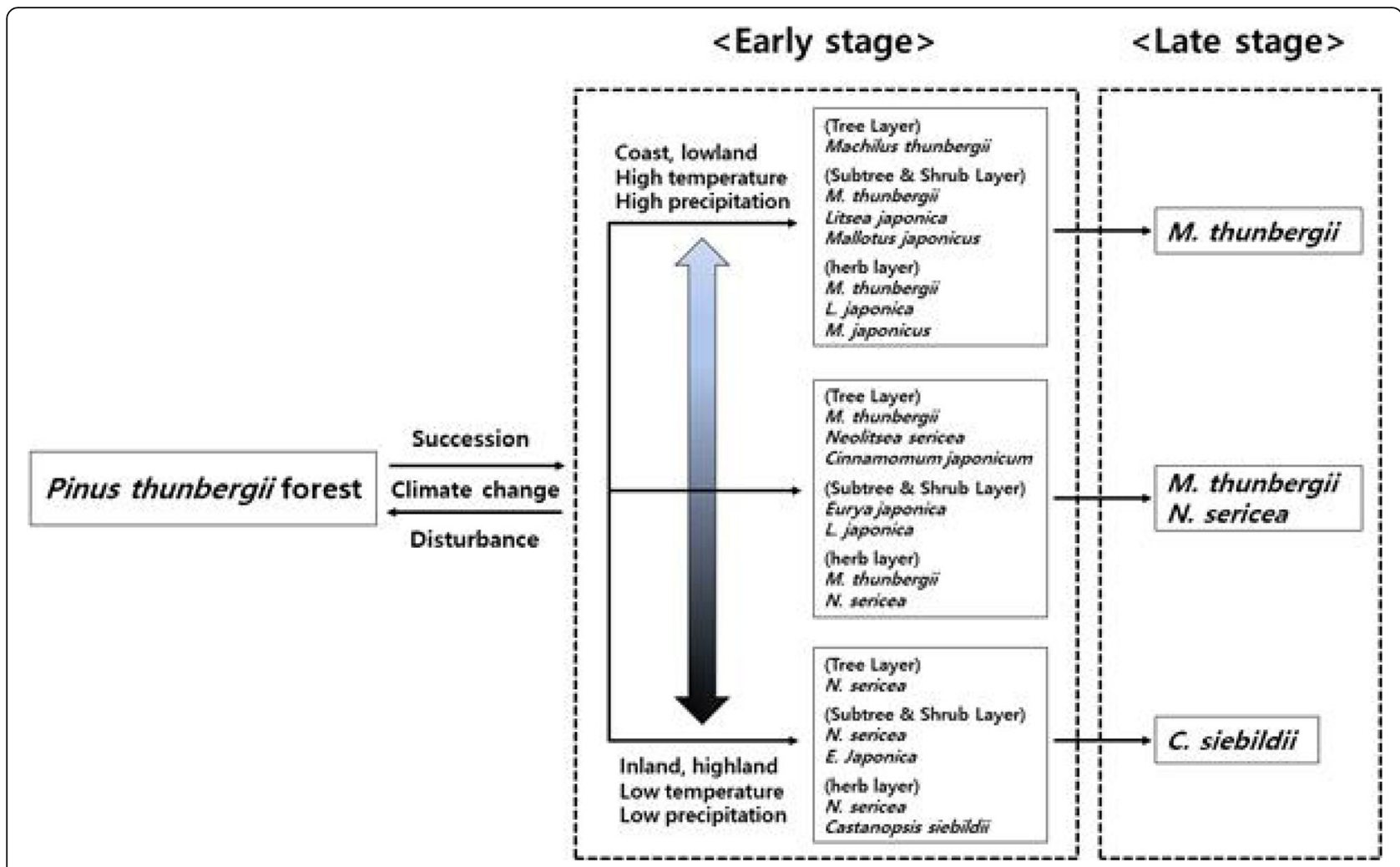

Fig. 8 Successional series in $P$. thunbergii forest of Jeju Island

The secondary succession stage in areas at relatively high altitudes above sea level (at least about $250 \mathrm{~m}$ ) where the effects of winds are weak will progress from Pinus thunbergii (early-successional species) to Neolitsea sericea and Eurya japonica (mid-successional species) and then to Castanopsis sieboldii (late-successional species).

Neolitsea sericea that is consistently supplemented by seedling and sapling in the understory vegetation will be dominated in the long term. However, the importance value of Neolitsea sericea in the herb layer decreases at higher altitudes, while the importance value of Castanopsis cuspidata in the herb layer increases.

However, in the intermediate succession intermediate stage, different tree species will adapt according to diverse location environmental conditions, and the progression of succession will show different distinct characteristics by site because the interactions among organisms, climates, terrains, and humans are different by site where young plants settle.

In this study, Machilus thunbergii is judged to be distributed in sites, which are lowlands (altitudes not higher than about $200 \mathrm{~m}$ ) adjacent to the coast where the climates are mild and affected by tidal winds, and Neolitsea sericea is judged to be distributed in sites at higher altitudes above sea level than the sites of Machilus thunbergii, which are far from the coast so that the effects of tidal winds are weak and temperatures are relatively low than the sites of other tree species (Hattori 1993; Oh and Jee 1995). However, plant groups in lowlands, where the types of external disturbances are relatively diverse, will form a toposequence in which mosaic patterns are formed depending on those tree species that adapted to the location environment or form edaphic climaxes due to microenvironmental factors resulting from differences in the terrains such as the coast and exposed rock lands as with Machilus thunbergii and Neolitsea sericea (Park et al. 2018).

Hattori (1992 1993) divided dominant tree species in warm temperate evergreen broad-leaved forests into types such as Machilus thunbergii forests, Castanopsis sieboldii forests, and Quercus myrsinaefolia Blume forests. Among them, Machilus thunbergii, Neolitsea sericea, and Cinnamomum japonicum, which are dominant species in the type Machilus thunbergii forests, were regarded to be dominant in mixture with each other because they are spread by eaters and have similar ecological statuses based on the tolerance to salinity due to tidal winds, and the prediction was identical to the dominance values shown by these tree species in the understory vegetation of lowland Pinus thunbergii forests.

In addition, Castanopsis sieboldii forests or mixed forests where other species live in mixture with Castanopsis 
sieboldii have already been reported as late-successional species or the late succession stage by many previous studies (Han et al. 2004; Kamijo et al. 2002; Hattori et al. 2012 Park et al. 2018). The location environments of these forests were slightly dry areas such as slopes and ridges (Hattori 1993; Choi 2012) and were correlated with altitudes above sea levels. That is, coastal lowlands were dominated by Machilus thunbergii forests and Castanopsis sieboldii forest appeared in highland areas. This was identical to the tree species distribution appearing in the tree layer of the primitive forests in Kyushu, Japan, which is a warm temperate evergreen broadleaved forest zone (Miyawaki 1981).

In this study, the appearance frequency of seedlings of Castanopsis sieboldii was high in the herb layer of stands at relatively high altitudes above sea level where the effects of tidal winds are weak because they are closer to the inland area than the coast. This is because Castanopsis sieboldii adapted to the lowlands in the inland area so that it was distributed there because it is vulnerable to tidal winds (Park et al. 2018). However, the survival rate of seedlings of Castanopsis sieboldii was higher than that of Machilus thunbergii because the nutrient consumption of seeds was small under low-luminosity conditions (Hiroki 2016). In addition, whereas the branches and leaves (shoots) of Machilus thunbergii, Neolitsea sericea, and Cinnamomum japonicum, which are midsuccessional species, are intensively distributed in the upper part of tree crowns through vertical growth, the branches and leaves of Castanopsis sieboldii avoid selfshading through horizontal growth to increase lightreceiving efficiency (Rahman et al. 2013). Therefore, if the seeds of Neolitsea sericea and Machilus thunbergii, which are bird-spreading types, are not continuously supplied in the process of progression of succession hereafter, the succession to Castanopsis sieboldii will gradually progress.

\section{Acknowledgements}

This work was supported by the research grant of the National Institute of Forest Science in 2019.

This work was supported by the National Research Foundation of Korea (NRF) grant funded by the Korea government (MSIT) (No. NRF-

2018R1A2B5A01021358).

\section{Authors' contributions}

All authors conducted a survey together during the study period. HHS wrote the manuscript. YYH participated in the design of the study and examined the manuscript. All authors read and approved the final manuscript.

\section{Funding}

This work was supported by the research grant of the National Institute of Forest Science in 2019

This work was supported by the National Research Foundation of Korea (NRF) grant funded by the Korea government (MSIT) (No. NRF-

2018R1A2B5A01021358).

Availability of data and materials

Not applicable
Ethics approval and consent to participate

Not applicable.

\section{Consent for publication}

Not applicable.

\section{Competing interests}

The authors declare that they have no competing interests.

\section{Author details}

'Korea Environmental Preservation Association, Daejeon 35235, Republic of Korea. ${ }^{2}$ Department of Life Science, Kongju National University, Gongju

32588, Republic of Korea. ${ }^{3}$ Forest Technology and Management Research Center National Institute of Forest Science, Pocheon-si 11186, Republic of Korea. ${ }^{4}$ National Institute of Ecology, Seochon 33657, Republic of Korea.

Received: 16 November 2019 Accepted: 5 December 2019

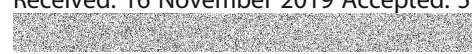

\section{References}

Allen RB, Partridage TR. Effects of spring and autumn fires on the composition of Chionochlora rigida tussock. New Zealand. Vegetatio. 1988;76(1-2):37-44.

Baek SM. The vegetation structure of Pinus thunbergii forest on the east-coast in Korea. Gyungsang Nat Univ Jinju Master thesis. 1996:8-13.

Barbour MG, Burk JH, Pitts WD, Gilliam and Schwartz. Terrestrial plant ecology. Seoul: Hongrung publishing company; 2015.

Bernard JM, Seischab EK, Gauch GG. Gradient analysis of the vegetation of the Byron-Bergen swamp, a rich fen in western New York. In: Peet RK, editor. Plant community ecology: Papers in honor of R.H. Dordrecht: Whittaker, Dr W. Junk Publ; 1985.

Box EO. Some similarities in the climates and vegetation of central Honshu and central eastern north America. In: Contributions to the knowledge of flora and vegetation of Japan proceedings of the 18th international phytogeographic excursion (IPE), 1984, through central Japan. Zürich: Geobotan. Inst. ETH, Stiftung Rübel; 1988.

Braun-Blanquet, Plant sociology. The study of plant communities. New York: Hafner Publish; 1965.

Bray JR, Curtis JT. An ordination of the upland forest of the Southern Winsconsin. Ecological monographies; 1957. p. 325-49.

Brower JE, Zar JH. Field and laboratory methods for general ecology. Dubuque: Wm. Brown Company; 1977.

Bunyavejchewin S. Structure and dynamics in seasonal dry evergreen forest in northeastern Thailand. J Veg Sci. 1999;10:787-92.

Cha JW. The vertical distribution of the vegetation on Mt. Hanla. J Plant Biol. 1969;12(4):19-29.

Choi KI, Jung SC, Youn HJ, Byeon JG, Joo SH. Community structure of Pinus thunbergii stand in the eastern coast of Gyeongsangbuk-do. J Agric Life Sci. 2012;46(4):57-68

Cho SY, Nam HY, Choi CY, Chae HY. Effects of seed ingestion by brown-eared bulbuls (Microscelis amaurotis) on the Ligustrum japonicum seed germination. Korea Journal of Orni. 2011;18(3):241-7.

Choi BK. Syntaxonomy and syngeography of warm-temperate evergreen broadleaved forests in Korea. Doctor's thesis: Keimyung Univ; 2012.

Choi CY, Chae HY. Effects of bird ingestion on seed dispersal and germination of the Elaeagnus macrophylla. Journal of Korean Society of Forest Science. 2007:96(6):633-8

Fuziwara K. Phytosociolgical investigation of the evergreen broad-leaved forests of Japan I. Bull Inst Environ Sci Technol. 1981;7(1):67-133.

Fuziwara K, Box EO. Evergreen broad-leaved forests in Japan and Eastern North America: vegetation shift under climatic warming. In: Klotzli F, Walther GR, editors. Recent shifts in vegetation boundaries of deciduous forests, especially due to general global warming; 1999.

Gauch HG, Whittaker RH. Comparison of ordination techniques. Ecology. 1972; 53(5):868-75.

Ha WY. Dynamics of individual population and communites structure of Pinus thunbergii forests at the western coast in Korea. Master thesis. Gyungsang Nat Univ Jinju. 1998:1-5.

Han BH, Kim JH, Bae JH. Restoration for evergreen broad-leaved forests by successional trends of pasture-grassland in the Seonheulgot, Jeju-do. Kor J Environ Ecol. 2004;18(4):369-81. 
Hattori T. Synecological study on Persea thunbergii type forest: I. geographical distribution and habitat conditions of Persea thunbergii forest. Jpn J Ecol. 1992;42(3):215-30.

Hattori T. Synecological study of Persea thunbergii- type forest: II. Geographical distribution and habitat conditions. Jpn J Ecol. 1993;43(2):99-109.

Hattori T, Minamiyama N, Matsumura T. Comparison of species composition and species richness between lucidophyllous forests at their northern and upper distributional limits. Vegetation Science. 2008;25(1):25-35.

Hattori T, Minamyama N, Iwakiri K, Tochimoto D. Primary succession in the lucidophyllous forest zone with special reference to the lava flows in Sakurajima, Japan. Vegetation Science. 2012;29(2):75-90.

Hill MO, Gauch HG. Detrended correspondence analysis: an improved ordination technique. Classification and ordination. Dordrecht: Springer; 1980. p. 47-58.

Hiroki F. Survival term differences of seedlings between Castanopsis sieboldii and Machilus thumbergii under low light conditions. Ann Coll Gen Educ Aichi Univ. 2016;51:1-6.

Hoshi N, Miyamoto T, Mochida Y, Tohyama M. Studies on the vegetation of sogayama hills in Odawara city, Kanagawa prefecture: a study of laurel forests in the coast of Sagami bay, Kanagawa Pref. (4). Reports of the Manazuru Marine Lab. Sci Edu Fac Educ Hum Sci Yokohama Univ. 1998;11:33-52.

Huang C, Moral R. Plant-environment relationships on the Montlake wildlife area, Seattle, Washington, USA. Vegetatio. 1988;75(1-2):103-13.

lehara T, Miyata I, Sugimura Y. Vegetation structure of natural forests docinated by Castanopsis cuspidata var. siebolkii in Izumo area. San-in region: I. Stand and species ordination by means of principal component analysis. Japanese Journal of Ecology. 1983;33(2):109-119.

Ishida H, Hattori T, Takeda Y. Comparison of species composition and richness among primeval, natural, and secondary lucidophyllous forests on Tsushima Island, Japan. Vegetation Sci. 2005;22(1):1-14.

Jeju Island special self-governing province. 2014. Jeju special self-governing province statistical yearbook. www.jeju.go.kr

José RA, Maria DP, Carlos A, Alfredo B, Juan DD, Antonio G, Maria FP. Laure forest recovery during 20 years in an abandoned firebreak in Tenerife, Canary Islands. Acta Oecologica. 2008;33:1-9.

Kamijo T, Kitayama Y, Sugawara A, Urushimichi S, Sasai K. Primary succession of the warm-temperate broad-leaved forest on a volcanic island, Miyake-jima, Japan. Folia Geobotanica. 2002;37:71-91.

Kang SJ. Ecological studies on the burned fields in Korea. Tohoku Univ. Ph. D. Thesis; 1982

Kim EM, Kang CW, Won HK, Song KM, Oh MR. The status of fruits consumed by brown-eared bulbul (Hypsypetes amaurotis) as a seed dispersal agent on Jeju Island. J Korean Environ Restoration Technol. 2015;17(1):53-69.

Kim JK, Lee SK, Min HK, Oh KCA. Study on food resource and utilization of artificial nest of wild-birds in urban woodland. Korea Ecol. 2002;25(5):275-82.

Kim JU, Kil BS. A study on the distribution of Pinus thunbergii in the Korean peninsula. Korea J Ecol. 1983;6:45-54

Kim MH, Park CM, Jang KK. An analysis of correlation between Pinus thunbergii forests and soil conditions by TWINSPAN and CCA ordination in west coast of South Korea. J Korean Env Res Tech. 2016;19(1):45-59.

Kim SH. Ecological characteristics of Japanese black pine (Pinus thunbergii) forests of east coastal sand dunes in KOREA. Seoul: Seoul National University. Doctor thesis; 2003.

Kim YS, Ko SC, Choi BH. Distribution atlas of plants of Korea. Kor J PI Taxon. 1981; $1: 53-76$

Kim YS, Oh KK. Restoration model of evergreen broad-leaved forests in warm temperate region (II)-rare, endangered and naturalized plants. Korean J Environ Ecol. 1996;10(1):128-39.

Kimmins JD. Forest ecology. N.Y: Macmillan Publishing Company; 1987.

Klötzli F. On the global position of the evergreen broad-leaved (nonombrophilous) forest in the subtropical and temperate zones. Geobot. Inst. ETH, Stiftung Rübel, Zürich. 1988;98:169-96.

Korea national arboretum. Korean plant names index committee. 2017.

Kuroda A, Ishida H, Iwakiri K, Fukui S, Hattori T. Comparison of species composition and species richness among Cryptomeria japonica plantations, secondary lucidophyllous forests, and primeval lucidophyllous forests in the lowland parts of Yakushima Island, South Japan. Vegetation Science. 2015;32:95-116.

Kwon JO, Lee KJ, Jang SH. The planting models of maritime forest by the plant community structure analysis in the seaside, Incheon-a case study on Pinus thunbergii community and $P$. densiflora community. J Korean Inst Landscape Arch. 2004:31(6):53-63.

Lee CB. Coloured flora of Korea I volumes. Seoul: Hyangmunsa; 2003a.
Lee CB. Coloured flora of Korea II volumes. Seoul: Hyangmunsa; 2003b.

Lee KJ, Gu KH, Choi JS, Cho HS. Analysis on the forest community of Daewon Vally in Mt. Chiri by the classification and ordination techniques. Korean Soc Environ Ecol. 1991:5:54-69.

Lee KJ, Jo JC, Ryu CH. Analysis on the structure of plant community in Mt. Yongmun by classification and ordination techniques. J Plant Biol. 1990a; 33(3):173-82

Lee KJ, Jo ZY, Lee BS, Lee DS. The structure of plant community in Kwangnung Forest (I) - analysis on the forest community of Soribong area by the classification and ordination techniques. J Korean Forest Soc. 1990b;79(2): 173-86.

Lee $\mathrm{K}$, Ryu $\mathrm{CH}$, Choi SH. The structure of plant community on Orimok, Yongsil and Donnaeko area in Mt. Halla. Korean Soc Environ Ecol. 1992; 6:25-43.

Lee KS. Mechanisms of vegetation succession on abandoned fields after shifting cultivation in Chinbu, Kangwon-Do. Seoul National Univ. Ph. D. Thesis; 1995.

Lee KS, Cho DS. The effects of microenvironmental heterogeneity on the spatia distribution of herbaceous species in a temperate hardwood forest. Korean J Ecol. 2000;23(3):255-66.

Lee KS, Jeong YS, Kim SC, Shin SS, No CH, Pack SD. Development of vegetation structure after forest fire in the east coastal region, Korea. Korean J Ecol. 2004;27(2):99-106.

Lee KY, Kwon YH. The structure of vegetation of the Pinus thunbergii. J of Gyungsang Nat Univ Jinju. 1988;27:237-45.

Masaka K, Sato H, Kon H, Fukuchi M. Demographic and height growth response of native broad-leaved deciduous tree saplings to overhead canopy release in a coastal Pinus thunbergii forest in Hokkaido, northern Japan. J For Res. 2012:17(5):421-31.

McCune, B and Mefford M.J. PC-ORD. Multivariate analysis of ecological data. MJM Software Design, Gleneden Beach; 2006.

Miyawaki A. Vegetation of Japan Vol. 1 Yakusima. Tokyo: Shibundo.co, LTD. Publishers; 1980.

Miyawaki A. Vegetation of Japan Vol. 3 Shikoku. Tokyo: Shibundo. Co, LTD. Publishers; 1981.

Moermond TC, Denslow J. Neotropical avian frugivores: patterns of behavior, morphological and nutrition, with consequences for fruit selection. Ornithol Monogr. 1985;36:865-97.

Mucina L, Pignatti S, Rodweel JS, Schaminee JH, Chytry M. European vegetation survey: case studies. uppsala: Opuluspress; 1997.

Nakashima Y. Situations and problems of coastal forest in Japan. In: Proceeding of Joint Seminar of Korean Society of Coastal Forest and Japanese Society of Coastal Forest; 2005. p. 7-10.

National Institute of Biological Resources. National species list of Korea; 2018.

National Institute of Forest Science. Status of coastal disaster prevention forest in Korea (I), vol. 123; 2013

Oh KK, Cho W. Vegetation structure of warm temperate evergreen forest at Ch'omch'aksan, Chindo, Korea. Korean J Ecol. 1996;10(1):66-75.

Oh KK, Choi SH. Vegetational structure and successional sere of warm temperate evergreen forest region, Korea. Korean J Ecol. 1993;16(4):459-76.

Oh KK, Jee YG. Plant community structure of evergreen broad-leaved forest in (Mt.) Pulgapsan, Korea. J Korean Appl Ecol. 1995:9(1):30-41.

Oh KK, Kim YS. Restoration model of evergreen broad-leaved forests in warm temperate region(1)-vegetational structure. Korean J Environ Ecol. 1996;10(1): 87-102.

Olsvig-Whittaker L, Scachak MM, Yair A. Vegetation patterns related to environmental factors in Neger desert watershed. In: Peet RK, editor. Plant community ecology: papers in honor of R.H. Whittaker, Dr W. Junk Publ; 1983.

Park CM, Kim SW, Park SH. Study on growth characteristics of Pinus thunbergii windbreak forests around Goosipo beach, Gochang-gun. Korea J Environ Ecol. 2009;23(4):365-75.

Park G, Lee D, Seo Y, Choi J. Height growth models for Pinus thunbergii in Jeju Island. J Environ Sci. 2015;31:255-60.

Park $1 \mathrm{H}$. A study on forest structure and biomass in Baegwoonsan natural ecosystem. Doctor's thesis, Seoul National Univ; 1985.

Park JH, Lee KS, Yoo BO, Kang YJ, Ryu SB, Jung SY, Bae EJ. Vegetation structure and growth characteristics of Pinus thunbergii stands in Korea. J Agr Life Sci. 2013;47(5):135-45.

Park SG, Choi SH, Lee SC. A review of vegetation succession in warm-temperate evergreen broad-leaved forests -focusing on Actinodaphne lancifolia community. Korea J Environ Ecol. 2018;32(1):77-96. 
Rahman L, Umeki K, Honjo T. Architectural differences among shaded saplings of four evergreen broad-leaved tree species in Japan. Pap Environ Inf Sci. 2013; 27:5-10

Sasaki T, Koyama A, Koyanagi T, Furukawa T, Uchida K. Data analysis of plant community structure and diversity. Handbook of methods in ecological research 3: Kyritsu Publishing Co; 2015.

Song YC. Broad-leaved evergreen forests in Central Japan in comparison with eastern China. Zürich: Geobot. Inst. ETH. Stiftung Rübel; 1988.

Song YC, Da LJ. Vegetation structure and function at multiple spatial, temporal and conceptual scales. Part 2: evergreen broad-leaved forest of East Asia. Switzerland: Springer International Publishing; 2016. p. 101-28.

Stanfield BJ, Blis JC, Smith CL, and Spies TA. 2001. Forest ownership diversity and forest cover diversity in the Oregon Coast Range. http:/www.cof.orst.edu/cof/ $\mathrm{fr} /$ people/diverse.htm

Suzuki E, Numata M. Sucesion on a sandy coast following the construction of banks planted with Elymus molis. Jap Jour Eco. 1982;32:129-42.

Tabata K, Hashimoto H, Morimoto Y. The effects of initial size and competing trees on the growth of Quercus glauca Thunb. and Quercus myrsinaefolia Blume in a large-scale mature urban forest. J. Jpn. Soc. Reveget. Tech. 2015; 42(1):97-102.

Taoda H. Succession of Pinus thunbergii forest on coastal dunes, Hitotsuba Coast, Kyushu, Japan Hikobia 10; 1988. p. 119-28.

Taylor SJ, Carleton TJ, Adams P. Understory vegetation changes in a Picea mariana chronosequence. Vegetatio. 1987;73(2):63-72.

Wang CW. The forests of China with a survey of grassland and desert vegetation. Beiiing: Maria Moors Cabot Foundation Publication; 1961.

Westman WE. Xeric Mediterranean-type shrubland associations of Alta and Baja California and the community/continuum debate. In: Peet RK, editor. Plant community ecology: papers in honor of R.H. Whittaker, Dr W. Junk Publ; 1985.

World Conservation Monitoring Centre(WCMC). Global Biodiversity: Status of the earth's living resources. Chapman \& Hall; 1992.

Worldclim-Global Climate Data. 2019. www.worldclim.org. Accessed 2019.

Yim KB. Forestry theory. Seoul: Hyangmunsa; 1989.

Yim YJ, Kim JU, Lee NJ, Kim YB, Paek KS. Phytosociological classification of plant communities on Mt, Halla National Park, Korea. Korean J Ecol. 1990;13(2):101-30.

Yim YJ, Kira T. Distribution of forest vegetation and climate in Korea peninsula I. distribution of some indices of thermal climate. Jpn J Ecol. 1975;25(2):77-88.

You YH, Lee CH. Early vegetation succession in abandoned field in Cheju Island. Korean J Ecol. 2003;26(4):209-14.

\section{Publisher's Note}

Springer Nature remains neutral with regard to jurisdictional claims in published maps and institutional affiliations.

Ready to submit your research? Choose BMC and benefit from:

- fast, convenient online submission

- thorough peer review by experienced researchers in your field

- rapid publication on acceptance

- support for research data, including large and complex data types

- gold Open Access which fosters wider collaboration and increased citations

- maximum visibility for your research: over $100 \mathrm{M}$ website views per year

At $\mathrm{BMC}$, research is always in progress.

Learn more biomedcentral.com/submissions 